\title{
Okul Kültürü ve Örgütsel Muhalefet Davranışları Arasındaki İliş̧kinin Meslekî Değerler Aracılığıyla Araştırılması
}

\author{
Arş. Gör. Ayşegül KADI* \\ Ege Üniversitesi, Eğitim Fakültesi, Bornova / İzmir / Türkiye \\ Yrd. Doç. Dr. Osman Ferda BEYTEKIN \\ Ege Üniversitesi, Eğitim Fakültesi, Bornova / İzmir / Türkiye
}

\section{$\ddot{\mathbf{O} z}$}

$\mathrm{Bu}$ çalışmanın amacı; öğretmenlerin okul kültürüne ilişkin görüşleri ve örgütsel muhalefet davranışları arasındaki ilişkiye meslekî değerlerinin kısmî aracılık etkisinin incelenmesidir. Araştırmada, değişkenler arasındaki olası ilişkileri gösterecek model kurulmuş ve bu model yapısal eşitlik modellemesi ile test edilmiştir. Araştırmanın örneklemini, uygun örnekleme yöntemiyle belirlenen 575 öğretmen oluşturmaktadır. Araştırma sonucunda; öğretmenlerin örgütsel muhalefet davranışları ile okul kültürüne ilişkin görüşlerinin, öğretmenlerin meslekî değerleri ile okul kültürüne ilişkin görüşlerinin ve öğretmenlerin örgütsel muhalefet davranışları ile meslekî değerlerinin 
doğrudan ilişkili olduğu görülmüştür. Öğretmenlerin örgütsel muhalefet davranışları ile okul kültürü arasında doğrudan ilişki olduğu; ancak bu ilişkiye meslekî değerler dâhil edildiğinde, meslekî değerlerin kısmî aracı değişken olduğu bulunmuştur. Bu bağlamda okul yöneticilerinin örgütsel muhalefet ve meslekî değer değişkenlerini yönetsel uygulamalarında göz önünde bulundurabilecekleri önerilebilir. Ayrıca, okul kültürü üzerinde aracılık etkisi olan diğer değişkenler araştırılabilir.

Anahtar Kelimeler: Örgütsel muhalefet davranışları; Meslekî değerler; Okul kültürü.

\title{
A Research on the Partial Mediating Effect of Professional Values in the Relationship Between \\ Organizational Dissent Behaviors and School Culture
}

\begin{abstract}
Purpose of this study is to examine the partial mediating effect of professional values in the relationship between organizational dissent behaviors and opinions of teachers about school culture. A model shows the possible relationships among variables was constructed and this measurement model was tested by structural equation modelling. The research sample, as determined by convenience sampling method consists of 575 teachers. The results of structural equation modelling supported the proposed model. Based on these findings, hypothesis that organizational dissent behaviors and opinions about school culture of teachers are related directly was confirmed. Organizational dissent behaviors and opinions about school culture of teachers is negatively correlated. Hypothesis that professional values and opinions about school culture of teachers are related directly was confirmed. Professional values and opinions about school culture of teachers is positively correlated. Third hypothesis; organizational dissent behaviors and professional values of teachers are related directly was confirmed. Organizational dissent behaviors and professional values of teachers is positively correlated. Fourth hypothesis; there is a relationship between organizational dissent behaviors and opinions of teachers about school culture with the partial mediating effect of professional values is con-
\end{abstract}


firmed. In this context, school administrators may consider organizational dissent and professional values in administrative practices. In addition, other variables that have an impact on school culture can be investigated.

Keywords: Organizational dissent behaviors; Professional values; School culture.

\section{Extended Summary}

\section{Purpose}

Organizational culture directs the behavior of individuals and groups norms, attitudes, beliefs and habits (Eren, 2001). The activities carried out in schools are based on the interaction between members of the organization and school culture consists through this interaction (Erdem and İşbaş1, 2000). School culture is defined as rules that guide school administrator, teacher and students' behaviors, beliefs and values (Özdemir, 2006). School culture has the aim of ensuring a successful education and training and it can help teachers to understand the specific norms and values to contribute the school development and its effectivity (Atay, 2001). Organizational dissent can be described as a situation that members and their seniors experience dissents in an organization (Özdemir, 2010). Kassing (1998) revealed three strategies to express dissent. Understandable dissent can be defined as a dissent that is made the people in the organization clearly, secret dissent can be defined as a dissent that is employees want to express their ideas but there is no oppotunity for this situation and external dissent can be defined as a dissent that is without telling issues to any person in the organization to disagree with them (Özdemir, 2010). The purpose of this study is to examine the partial mediating effect of professional 
values in the relationship between organizational dissent behaviors and opinions of teachers about school culture. It is expected that examining the partial mediating effect of professional values in the relationship between organizational dissent behaviors and school culture is important to provide guidance for researchers, school administrators and teachers. It was proposed that teachers' organizational dissent behaviors may affect their opinions about school culture and professional values may have a partial mediating effect in this relationship. In the study, the hypothesis were tested as follows:

1. School culture and organizational behavior of teachers are directly related.

2. Professional values and opinions about school culture of teachers are directly related.

3. Organizational dissent behaviors and professional values of teachers are directly related.

4. There is a relationship between organizational dissent behaviors and opinions of teachers about school culture with the partial mediating effect of professional values.

\section{Method}

A model that shows the possible relationships among variables was constructed and this measurement model was tested by structural equation modelling. The accessible population of study consists of teachers who work at secondary schools in the 2013-2014 academic year in Buca and Torbal, İzmir. The research sample, as determined by convenience sampling method consists of 575 teachers. Data were 
collected by School Culture Inventory adapted by Ayık (2007), Organizational Dissent Scale developed by Özdemir (2010) and Professional Values Scale developed by Tunca and Sağlam (2013).

Organizational Dissent Scale: It consists of 17 items. Scale is answered as follow 1=Ever, 2=Rarely, 3=Sometimes, 4=Often, 5=Always. It was seen that the tool had a structure of three dimensions and total explained variance by the scale was $63.68 \%$. Cronbach Alpha coefficient of the scale is .76 .

Professional Values Scale: Scale is answered as follow 1=Does not reflect me at all, 2=Does not reflect me, 3=Reflects me partly, $4=$ Reflects me, $5=$ Reflects me very much. It consists of 24 items. It was seen that the tool had a structure of four dimensions and Cronbach Alpha coefficient of the scale is .82 .

School Culture Inventory: Scale is answered as follow 1=Strongly disagree, 2=Less agree, 3=Moderately agree, 4=Very much agree, $5=$ Fully agree. It was seen that the tool had a structure of six dimensions and it consists of 35 items. Cronbach Alpha coefficient of Collaborative Leadership is 0.89 , Cronbach Alpha coefficient of Teacher Collaboration is 0.76 , Cronbach Alpha coefficient of Professional Development is 0.75 , Cronbach Alpha coefficient of Common Purposes is 0.78, Cronbach Alpha coefficient of Peer Support is 0.67 Cronbach Alpha coefficient of Joint Learning is 0.62. Structural equation modeling was used with aim of testing the relationship between variables in the model. 


\section{Results}

Based on these findings, hypothesis that organizational dissent behaviors and opinions about school culture of teachers are related directly was confirmed. Organizational dissent behaviors and opinions about school culture of teachers is negatively correlated. Hypothesis that professional values and opinions about school culture of teachers are related directly was confirmed. Professional values and opinions about school culture of teachers is positively correlated. Third hypothesis; organizational dissent behaviors and professional values of teachers are related directly was confirmed. Organizational dissent behaviors and professional values of teachers is positively correlated. Fourth hypothesis; there is a relationship between organizational dissent behaviors and opinions of teachers about school culture with the partial mediating effect of professional values is confirmed.

\section{Discussion}

The results of structural equation modelling supported the proposed model. Based on these findings, hypothesis that organizational dissent behaviors and opinions about school culture of teachers are related directly was confirmed. Organizational dissent behaviors and opinions about school culture of teachers is negatively correlated. Teachers who adopted the culture may be more efficient at work. Hypothesis that professional values and opinions about school culture of teachers are related directly was confirmed. Professional values and opinions about school culture of teachers is positively correlated. It can be said that teachers' professional values are important to create a 
strong school culture. Third hypothesis; organizational dissent behaviors and professional values of teachers are related directly was confirmed. Organizational dissent behaviors and professional values of teachers is positively correlated. Teachers' organizational dissent behaviors are important to develop teachers' professional values. Fourth hypothesis; there is a relationship between organizational dissent behaviors and opinions of teachers about school culture with the partial mediating effect of professional values is confirmed.

\section{Conclusion}

In this context, school administrators may consider organizational dissent and professional values in administrative practices. In addition, other variables that have an impact on school culture can be investigated

\section{Giriş}

Bireyler bir amacı gerçekleştirebilmek için, farklı kimliklere sahip diğer insanlarla birlikte örgütler kurmaktadırlar. Artan rekabetle başa çıkabilmek için örgütler daha nitelikli bireylere ihtiyaç duyarlar. Bu yüzden, rutin çalışmaların dışına çıkabilen, büyük çaba gösteren bireylerin önemi giderek artmaktadır. Örgüt kültürü; bireylerin ve grupların davranışlarını yönlendiren normlar, davranışlar, inançlar ve alışkanlıklar bütünü olarak bilinmektedir (Eren, 2001; Hofstede, 2001). Schein (1984)'a göre, örgüt kültürü üyeler tarafindan geliştirilen ve paylaşılan temel varsayımlardır. Örgüt kültürünün temel ögeleri; değerler, normlar, inançlar, törenler, hikâyeler, mitler, kahramanlar, semboller ve dil olarak ele alınabilir. Her örgütteki kültür kendi ger- 
çekliği içinde örgüt üyeleri tarafından paylaşılan ve örgüte, biçim ve eylemlerine yön veren unsurlara sahiptir (Denison, 1990; Meek, 1988; Pettrigrew, 1979). Okullarda gerçekleştirilen etkinlikler, örgüt üyeleri arasındaki etkileşim temelli olmakta ve okul kültürü de bu etkileşim sayesinde oluşmaktadır (Erdem ve İşbaşı, 2000). Okul kültürü, bir okuldaki yönetici, öğretmen ve öğrencilerin davranışlarına kılavuzluk eden kurallar, inançlar ve değerler olarak tanımlanmaktadır (Özdemir, 2006). Başarılı eğitim ve öğretim sağlanması amacı ile okul kültürü; öğretmenlerin belirli normları ve değerleri anlamalarına, yöneticileri ile daha uyumlu çalışmalarına, okula daha fazla bağlanarak okula katkıda bulunmalarına, böylece verimliliğin artmasına yardımcı olabilir (Atay, 2001). Bireysel değerler; kişi açısından değerli ve önemli olanı; örgütsel değerler ise bir örgütün üyeleri tarafından kabul gören değerleri ifade etmektedir (Sezgin, 2007). Kişisel ve örgütsel değerlere ek olarak meslekî ve toplumsal değerler de örgüt kültürünün kalbi olarak görülür (D’Andrade, 2008; Lencioni, 2002; Posner, 2010). Okul kültüründen beslenen değerler, sosyal ve örgütsel hayatta yol gösterici konumundadır. Örgüt kültürü ile bütünleşen değerler, iş görenlerin davranışlarını yönetmede etkilidir (Çelik, 2000). Muhalefet, siyaset bilimine özgü bir kavram olarak kullanılırken yönetim bilimi dâhil olmak üzere pek çok disiplinin çalışma alanına girmiştir. Muhalefet kavramı "1. Bir tutuma, bir görüşe, bir davranışa karşı olma durumu, aykırılık. 2. Karş1 görüşte, tutumda olan kimseler topluluğu. 3. Demokraside iktidarın dışında olan parti veya partiler.” olarak tanımlanmaktadır (TDK, 2013). Örgütsel muhalefet, örgüt üyelerinin üstleri ile görüş ayrılığına düşmeleri durumu olarak ifade edilir (Özdemir, 2010). Örgütsel muhalefet zit 
düşüncelerin, farklı bakış açılarının açık bir biçimde ifade edilmesi anlamına gelir ve örgütsel süreçlerin doğal bir bileşeni olarak kabul edilir. Kassing (1998), muhalefeti ifade etmek için üç strateji ortaya koymuştur. Açık muhalefet, örgüt içerisinde düzeltmelere etki edebilecek kişilere anlaşılır bir şekilde muhalefeti, gizli muhalefet; çalışanların düşüncelerini dile getirmek istediklerini; ancak bunun için yeterli yolun olmadığını ifade eder. Dışsal muhalefet ise, örgüt içerisinde herhangi bir kişiye mes'eleyi anlatmadan ya da itiraz etmeden karşıt görüşte olmayı anlatır (Özdemir, 2010).

$\mathrm{Bu}$ çalışmanın amacı öğretmenlerin okul kültürüne ilişkin görüşleri ve örgütsel muhalefet davranışları arasındaki ilişkide meslekî değerlerinin kısmî aracılık etkisinin incelenmesidir. Öğretmenlerin okul kültürü hakkındaki görüşleri ve örgütsel muhalefet davranışları arasındaki ilişkinin meslekî değerler aracıllğ̆yla incelenmesinin eğitim kurumlarının etkililiği, başarısı ve verimliliğini artırma konusunda önemli olduğu düşünülmektedir. Araştırma kapsamında, test edilen hipotezler ise aşağıdaki gibidir:

1. Öğretmenlerin örgütsel muhalefet davranışları ile okul kültürü doğrudan ilişkilidir.

2. Öğretmenlerin meslekî değerleri ile okul kültürü doğrudan ilişkilidir.

3. Öğretmenlerin örgütsel muhalefet davranışları ile meslekî değerleri doğrudan ilişkilidir.

4. Öğretmenlerin örgütsel muhalefet davranışları ile okul kültürü 
öğretmenlerin meslekî değerleri aracılığı ile ilişkilidir.

\section{Yöntem}

\section{Araştırmanın Modeli}

$\mathrm{Bu}$ araştırma, ilişkisel bir araştırmadır. Ortaokullarda görev yapmakta olan öğretmenlerin örgütsel muhalefet davranışları, meslekî değerleri ve okul kültürü arasındaki ilişkiyi açıklamaya yönelik bir model ortaya koymaktadır. İlişkisel araştırmalar, korelasyonel istatistikleri kullanarak değişkenler arasındaki ilişkileri ortaya koyma amacında olan çalışmaları kapsar (Balcı, 2011).

\section{Evren ve Örneklem}

Araştırmanın evrenini, İzmir ili Buca ve Torbalı ilçelerinde ortaokul seviyesindeki resmi okullarda 2013-2014 Eğitim-Öğretim Y111'nda görev yapmakta olan öğretmenler oluşturmaktadır. Araştırmanın örneklemi ise, uygun örnekleme yöntemi ile belirlenen 575 öğretmen oluşturmaktadır. Uygun örnekleme yöntemi; zaman, para, iş gücü aç1sından var olan sınırlılıklar nedeniyle örneklemin kolay ulaşılabilir ve uygulama yapılabilir birimlerden seçilmesidir (Büyüköztürk, K11ıç-Çakmak, Akgün, Karadeniz ve Demirel, 2011).

\section{Veri Toplama Araçları}

Araştırmada veri toplama araçları olarak; Özdemir (2010) tarafından geliştirilen Örgütsel Muhalefet Ölçeği, Ayık (2007) tarafından uyarlanan Okul Kültürü Envanteri ve Tunca ve Sağlam (2013) tarafından geliştirilen Öğretmen Meslekî Değerler Ölçeği kullanılmıştır.

Örgütsel Muhalefet Ölçeği: Özdemir (2010) tarafindan geliştirilen ölçek formunda öğretmenlerin sergiledikleri 17 muhalif davranış yer 
almaktadır. Ölçek (1=Hiçbir zaman, 2=Nadiren, 3=Ara sıra, 4=Çoğunlukla, 5=Her zaman şeklinde) 5'li likert tipindedir. Faktör analizi sırasında ölçeğe ait üç faktörün birlikte varyansın \%63.68'ini açıkladığı saptanmıştır. Ölçek üç boyuttan oluşmaktadır. İlk boyut "haber uçurma" olarak isimlendirilmiştir ve bu boyuttaki örnek madde şöyledir: "Yöneticilerim ile görüş ayrıllğına düştüğüm durumlarda; üst makamlara gider, durumu onlara anlatırım.” İkinci boyut "açık muhalefet" olarak isimlendirilmiştir ve bu boyuttaki örnek madde şöyledir: "Yöneticilerim ile görüş ayrılığına düştüğüm durumlarda; yöneticinin kendisine itiraz ederim." Üçüncü boyut ise "örtük muhalefet" olarak isimlendirilmiştir ve "Yöneticilerim ile görüş ayrıllğına düştüğüm durumlarda; derslerim dışında okulda zaman geçirmem." Cronbach Alfa katsayısı ölçeğin bütünü için 0.76 'dir. Alt boyutlardan "Haber uçurma” boyutu için 0.76, “Açık muhalefet” boyutu için 0.77 ve “Örtük muhalefet" boyutu için ise 0.77 olarak bulunmuştur. Yapılan doğrulayıcı faktör analizi (DFA) sonucunda elde edilen uyum iyiliği indeksleri $\mathrm{x}^{2}=465.47, \quad \mathrm{sd}=116, \quad p=0.00, \quad \mathrm{NNFI}=0.94, \quad \mathrm{CFI}=0.95, \quad \mathrm{GFI}=0.91$, AGFI=0.89, S-RMR=0.07, RMSEA=0.07 olarak elde edilmiştir. $\mathrm{Bu}$ uyum iyiliği indeksleri test edilen model için model-veri uyumunun güçlü olduğunu göstermektedir.

Meslekî Değerler Ölçeği: Tunca ve Sağlam (2013) tarafından geliştirilen Öğretmen Meslekî Değerler Ölçeği (1=Beni hiç yansıtmıyor, 2=Beni yansitmiyor, 3=Beni kısmen yansitıyor, 4=Beni yansitiyor, 5=Beni çok yansıtıyor) şeklinde 5'li likert tipindedir. Ölçek, öğretmenlerin meslekî değerlerini içeren dört boyuttan oluşmaktadır. İlk boyut "farklılıklara saygı duyma" olarak isimlendirilmiştir ve bu bo- 
yuttaki bir örnek madde şöyledir: “Arkadaşlarını herhangi bir sebepten (anti sosyal olma, fiziksel özellikleri vb.) dolayı dışlayan öğrencileri uyarırım." İkinci boyut "kişisel ve toplumsal sorumluluk" olarak isimlendirilmiştir ve bu boyuttaki örnek madde şöyledir: "Huzur evi, çocuk esirgeme kurumu vb. sosyal hizmet kurumlarını belli aralıklarla ziyaret etmeye özen gösteririm." Üçüncü boyut "şiddete karşı olma" olarak isimlendirilmiştir ve bu boyuttaki örnek madde şöyledir: “Öğretimi engelleyen (yanındakiyle konuşma, sınıfta dolaşma vb.) öğrencilere gerektiğinde bağırırım”. Dördüncü ve son boyut ise "işbirliğine açık olma" olarak isimlendirilmiştir ve bu boyuttaki örnek madde şöyledir: "Çocuklarının öğrenmelerine destek olmaları için velilerle ortak çalışmalar yaparım”. Bu boyutlar toplam varyansın \%46.57'sini açıklamaktadır. Ölçeğin 24 maddesine verdikleri yanıtlardan elde edilen iç tutarlılık katsayısı .82 olarak belirlenmiştir. Ölçeği oluşturan dört boyutun iç tutarlılık katsayıları; "farklılıklara saygı duyma” için .77, "kişisel ve toplumsal sorumluluk" için .78, "şiddete karşı olma" için .70, "işbirliğine açık olma" için ise .72'dir. Yapılan doğrulayıcı faktör analizi (DFA) sonucunda elde edilen uyum iyiliği indeksleri $\mathrm{x}^{2}=1202.11, \mathrm{sd}=248, \quad p=0.00, \mathrm{NNFI}=0.91, \quad \mathrm{CFI}=0.92, \quad \mathrm{GFI}=0.85$, AGFI=0.82, S-RMR=0.07 RMSEA=0.08 olarak elde edilmiştir. $\mathrm{Bu}$ uyum iyiliği indeksleri test edilen model için model-veri uyumunun güçlü olduğunu göstermektedir.

Okul Kültürü Envanteri: Ayık (2007) tarafindan uyarlanan Okul Kültürü Envanteri (1=Hiç katılmıyorum, 2=Az katılıyorum, 3=Orta derecede katılıyorum, 4=Çok katılıyorum, 5=Tam katılıyorum) şeklinde 5'li likert tipindedir. Envanter 6 boyutludur ve 35 maddeden oluş- 
maktadır. İlk boyut "işbirliğine dayalı liderlik" olarak adlandırılmıştır ve bu boyuttaki örnek madde şöyledir: "Yöneticiler öğretmenlerin fikirlerine değer verir." İkinci boyut “öğretmen işbirliği” olarak adlandırılmıştır ve bu boyuttaki örnek madde şöyledir: "Öğretmenler konular ve seviyeler arasında diyalog ve plânlama imkânına sahiptir." Üçüncü boyut "meslekî gelişme" olarak adlandırılmıştır ve bu boyuttaki örnek madde şöyledir: "Öğretmenler sınıf öğretimi için araştırmalar ve bilgileri elde etmek amaciyla meslekî ağlardan (internet, uzman kişiler, meslekî kaynaklar vb.) yararlanırlar.” Dördüncü boyut “ortak amaçlar" olarak adlandırılmıştır ve bu boyuttaki örnek madde şöyledir: "Öğretmenler okulun misyonunu destekler." Beşinci boyut "meslektaş desteği”" olarak adlandırılmıştır ve bu boyuttaki örnek madde şöyledir: "Öğretmenler birbirlerine güvenirler." Altıncı boyut “ortak öğrenme” olarak adlandırılmıştır ve bu boyuttaki örnek madde şöyledir: "Öğretmenler ve veliler öğrenci performansı için ortak beklentilere sahiptirler.” Boyutlar için Cronbach Alfa değerleri İşbirliğine Dayalı Liderlik (0.89), Öğretmen İşbirliği (0.76), Meslekî Gelişme (0.75), Ortak Amaçlar (0.78), Meslektaş Desteği (0.67), Ortak Öğrenme (0.62) olarak hesaplanmıştır. Yapılan doğrulayıcı faktör analizi (DFA) sonucunda elde edilen uyum iyiliği indeksleri $x^{2}=2635.90$, $\mathrm{sd}=521, \quad p=0.00, \quad \mathrm{NNFI}=0.96, \quad \mathrm{CFI}=0.96, \quad \mathrm{GFI}=0.79, \quad$ AGFI=0.76, $\mathrm{S}-\mathrm{RMR}=0.06$, RMSEA=0.08 olarak elde edilmiştir. Bu uyum iyiliği indeksleri test edilen model için model-veri uyumunun güçlü olduğunu göstermektedir. 


\section{Verilerin Analizi}

Araştırmada ortaokullarda görev yapmakta olan öğretmenlerin örgütsel muhalefet davranışları, meslekî değerleri ve okul kültürleri arasındaki ilişkiyi açıklamak amacıyla yapısal eşitlik modellemesi tercih edilmiştir. Yapısal eşitlik modelleri özellikle psikometri, psikoloji, sosyoloji ve eğitim bilimlerinde değişkenler arasındaki ilişkilerin değerlendirilmesi ve kuramsal modellerin sınanmasında kullanılır (Hoyle, 1995; Tezcan, 2008).

Tablo 1. Standart Uyum İyiliği Ölçütleri

\begin{tabular}{lcc}
\hline Uyum Ölçüleri & İyi Uyum & Kabul Edilebilir Uyum \\
\hline RMSEA & $0 \leq \mathrm{RMSEA} \leq 0.05$ & $0.05 \leq \mathrm{RMSEA} \leq 0.08$ \\
SRMR & $0 \leq \mathrm{SRMR} \leq 0.05$ & $0.05 \leq \mathrm{SRMR} \leq 0.10$ \\
$\mathrm{NFI}$ & $0.95 \leq \mathrm{NFI} \leq 1.00$ & $0.90 \leq \mathrm{NFI} \leq 0.95$ \\
NNFI & $0.97 \leq \mathrm{NNFI} \leq 1.00$ & $0.95 \leq \mathrm{NNFI} \leq 0.97$ \\
CFI & $0.97 \leq \mathrm{CFI} \leq 1.00$ & $0.95 \leq \mathrm{CFI} \leq 0.97$ \\
GFI & $0.95 \leq \mathrm{GFI} \leq 1.00$ & $0.90 \leq \mathrm{GFI} \leq 0.95$ \\
AGFI & $0.90 \leq \mathrm{AGFI} \leq 1.00$ & $0.85 \leq \mathrm{AGFI} \leq 0.90$ \\
\hline
\end{tabular}

Doğrulayıcı faktör analizi ve modeli test etme sonucunda elde edilen uyum iyiliği değerlerinin yorumlanmasında, yukarıdaki kritik değerler kullanılmıştır (Schermelleh-Engel, Moosbrugger ve Müller, 2003).

\section{Bulgular}

Bu bölümde hipotezlere ilişkin elde edilen bulgular sunulmaktadır. Yapısal eşitlik modeli analizinde farklı iki yaklaşım izlenmektedir. 
İki merhaleli ve tek merhaleli analiz yaklaşımı olarak bilinen bu yaklaşımlar, modelin bütünsel olarak nasıl analiz edileceğini açıklamaktadır. Tek merhaleli yaklaşımda kuramsal araştırma modelinin bütün unsurları aynı anda analiz safhasına ilâve edilerek yapısal eşitlik modeline ilişkin sonuçların tamamının elde edilmesi sağlanır. İki merhaleli yaklaşımda ise, ölçüm modeli ve yapısal model ayrı ayrı test edilmektedir. İki merhaleli yaklaşımın ilk merhalesi doğrulayıcı faktör analizi olarak da ele alınabilir. Öncelikle ölçüm modelinin istatistiksel uygunluğunun değerlendirilebilmesi için uygun modelin elde edilmesine kadar analizler tekrarlanır daha sonra yapısal model için gerekli işlemler gerçekleştirilir (Y1lmaz ve Çelik, 2009). Bu araştırmada da iki merhaleli yaklaşım benimsendiği için araştırmanın bu kısmında ölçüm modelinin uygunluğu istatistiksel olarak değerlendirildikten sonra yapısal modele ilişkin analizlerin yapıldığı ikinci merhaleye geçilmektedir.

Modelin betimlenmesi merhalesinde, önerilen model araştırma hipotezlerine göre kurulmuştur. Bu adımda, örtük yapıyı betimleyen faktör ve değişkenler belirlenmiştir. Bu araştırmada toplam 3 örtük ve 13 gözlenen değişken bulunmaktadır. Modelde öğretmenlerin örgütsel muhalefet davranışları araştırmanın bağımsız değişkenini, meslekî değerleri aracı değişkenini, okul kültürü görüşleri ise bağımlı değişkenini oluşturmaktadır. Model betimleme, var olan ilgili kuram, araştırma ve bilginin kullanılmasını ve kuramsal bir modelin geliştirilmesini, var olan kuramsal modelde hangi değişkenlerin yer alacağı ve bunların birbirleriyle ilişkisini anlatır (Topkaya, 2011). 
Model tanımlama merhalesinde, modelde yer alan örtük değişkenlerin aralarındaki ikili korelasyonlar incelenmiştir.

Tablo 2. Örtük Değişkenlerin İkili Korelasyonları

\begin{tabular}{lcc}
\hline & Meslekî değer & Muhalefet davranışları \\
\hline Okul kültürü & $.192^{* *}$ & $-.138^{* *}$ \\
Meslekî değer & 1 & $.156^{* *}$ \\
Muhalefet davranışları & & 1 \\
\hline
\end{tabular}

Tablo 2'de görüldüğü gibi örtük değişkenler arasında istatistiksel olarak anlamlı ilişkiler bulunmaktadır. Model tanımlama merhalesinde, gözlenen değişkenlerin ikili korelasyonları da elde edilmiştir.

Tablo 3. Gözlenen Değişkenlerin İkili Korelasyonları

\begin{tabular}{|c|c|c|c|c|c|c|c|c|c|c|c|c|c|}
\hline & 1 & 2 & 3 & 4 & 5 & 6 & 7 & 8 & 9 & 10 & 11 & 12 & 13 \\
\hline Haber uçurma & 1 & $.359^{* *}$ & $.446^{* *}$ & -.039 & $.128^{* * *}$ & $.203^{* *}$ & .007 & -.060 & -.045 & $-.120^{\circ}$ & $-.115^{\prime \prime}$ & -.075 & .026 \\
\hline Açık muhalefet & & 1 & $.284^{* *}$ & $.253^{* *}$ & $.182^{* * *}$ & .077 & $.158^{* *}$ & .016 & -.002 & -.031 & -.026 & -.036 & .065 \\
\hline Örtük muhalefet & & & 1 & $-.086^{\circ}$ & -.058 & $.320^{* *}$ & -.065 & $-.191^{*}$ & $-.175^{*}$ & -.225 & -.212 & -.113 & $-.090^{*}$ \\
\hline Farkl11ıklara sayg1 & & & & 1 & $.508^{* *}$ & .025 & $.488^{\prime \prime}$ & .062 & .061 & $.131^{* *}$ & $.144^{* *}$ & .056 & $.086^{*}$ \\
\hline Kişisel ve toplumsal & & & & & 1 & -.033 & $.641^{\cdots}$ & $.190^{\prime \prime}$ & .209 & $.224^{* *}$ & $.192^{* *}$ & $.138^{* *}$ & $.235^{* *}$ \\
\hline Şiddete karşı & & & & & & 1 & -.061 & .006 & -.018 & -.057 & -.079 & -.040 & $-.083^{*}$ \\
\hline İşbirliğine açık & & & & & & & 1 & $.185^{\prime \prime}$ & .174 & $.235^{* *}$ & $.204^{* *}$ & $.108^{* *}$ & $.329^{* *}$ \\
\hline İşbirliğine dayalı & & & & & & & & 1 & $.720^{* *}$ & $.714^{* *}$ & $.733^{* *}$ & $.603^{* *}$ & $.579^{* *}$ \\
\hline \multicolumn{14}{|l|}{ liderlik } \\
\hline Öğretmen işbirliği & & & & & & & & & 1 & $.744^{* *}$ & $.668^{* *}$ & $.698^{* *}$ & $.563^{* *}$ \\
\hline Meslekî gelişme & & & & & & & & & & 1 & $.753^{* *}$ & $.702^{* *}$ & $.593^{* * *}$ \\
\hline Ortak amaçlar & & & & & & & & & & & 1 & $.634^{* *}$ & $.602 *$ \\
\hline Meslektaş desteği & & & & & & & & & & & & 1 & $.525^{* *}$ \\
\hline Ortak öğrenme & & & & & & & & & & & & & 1 \\
\hline
\end{tabular}


Tablo 3 incelendiğinde, gözlenen değişkenler arasında istatistiksel olarak anlamlı ilişkiler bulunmaktadır.

Modelin tanımlanması merhalesinde değişkenler arasındaki ilişkiler test edilmiş ve ölçüm modeli oluşturulmuştur.

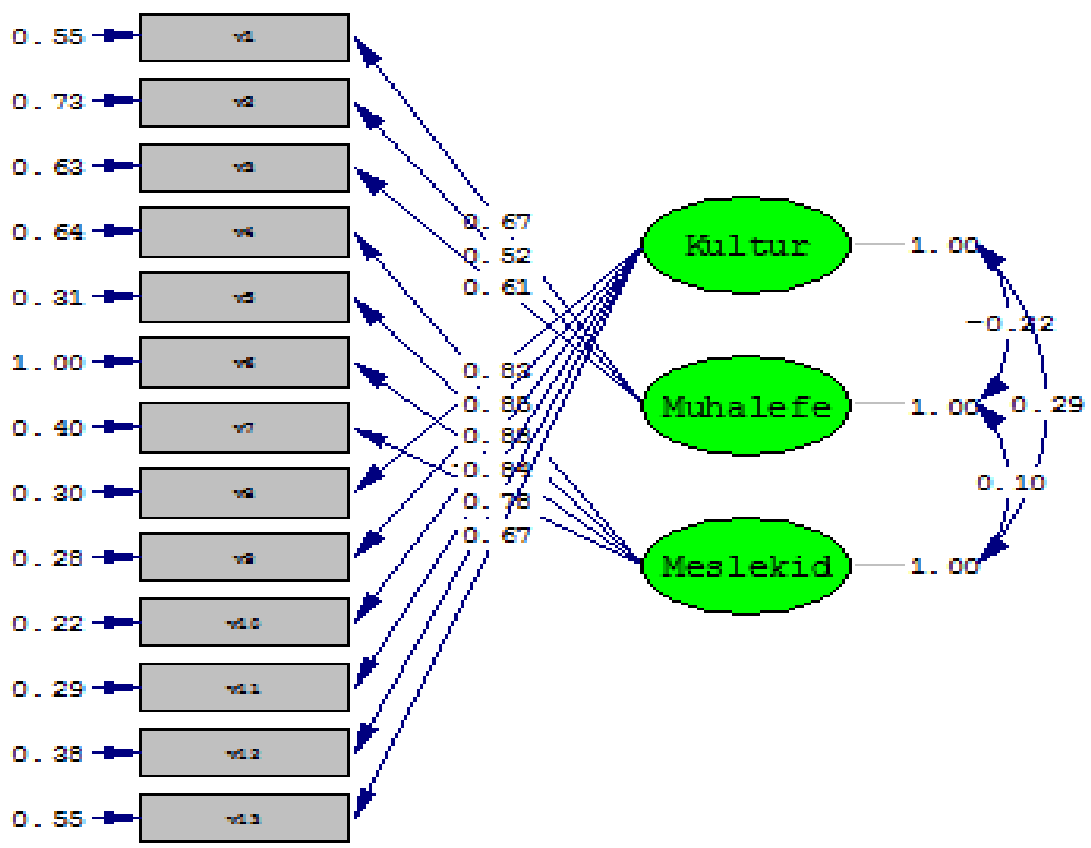

Şekil 1. Öğretmenlerin okul kültürüne ilişkin görüşleri ve örgütsel muhalefet davranışları arasındaki ilişkide meslekî değerlerin aracılığı ölçüm modeli.

Şekil 1'de öğretmenlerin örgütsel muhalefet davranışları, meslekî değerleri, okul kültürü görüşlerine ilişkin örtük yapıların ölçüm modelleri bütünleşik olarak doğrulayıcı faktör analizi ile test edilmiştir. Ölçüm modeli için yapılan doğrulayıcı faktör analizi sonucu modelin uyum iyiliği istatistikleri incelendiğinde $\mathrm{x}^{2}=321.47, \mathrm{sd}=62, p=0.00$, 
$\mathrm{CFI}=0.94, \mathrm{AGFI}=0.88, \mathrm{NFI}=0.93, \mathrm{~S}-\mathrm{RMR}=0.07, \mathrm{RMSEA}=0.08 \mathrm{de}-$ ğerlerinin kabul edilebilir uyum düzeyine işaret ettiği görülmektedir (Kline, 2011). Bu uyum iyiliği indeksleri test edilen modeli için model-veri uyumunun sağlandığını göstermektedir.

Şekil 2'de öğretmenlerin okul kültürüne ilişkin görüşleri ve örgütsel muhalefet davranışları arasındaki ilişkinin meslekî değerleri aracılığı modeli görülmektedir.

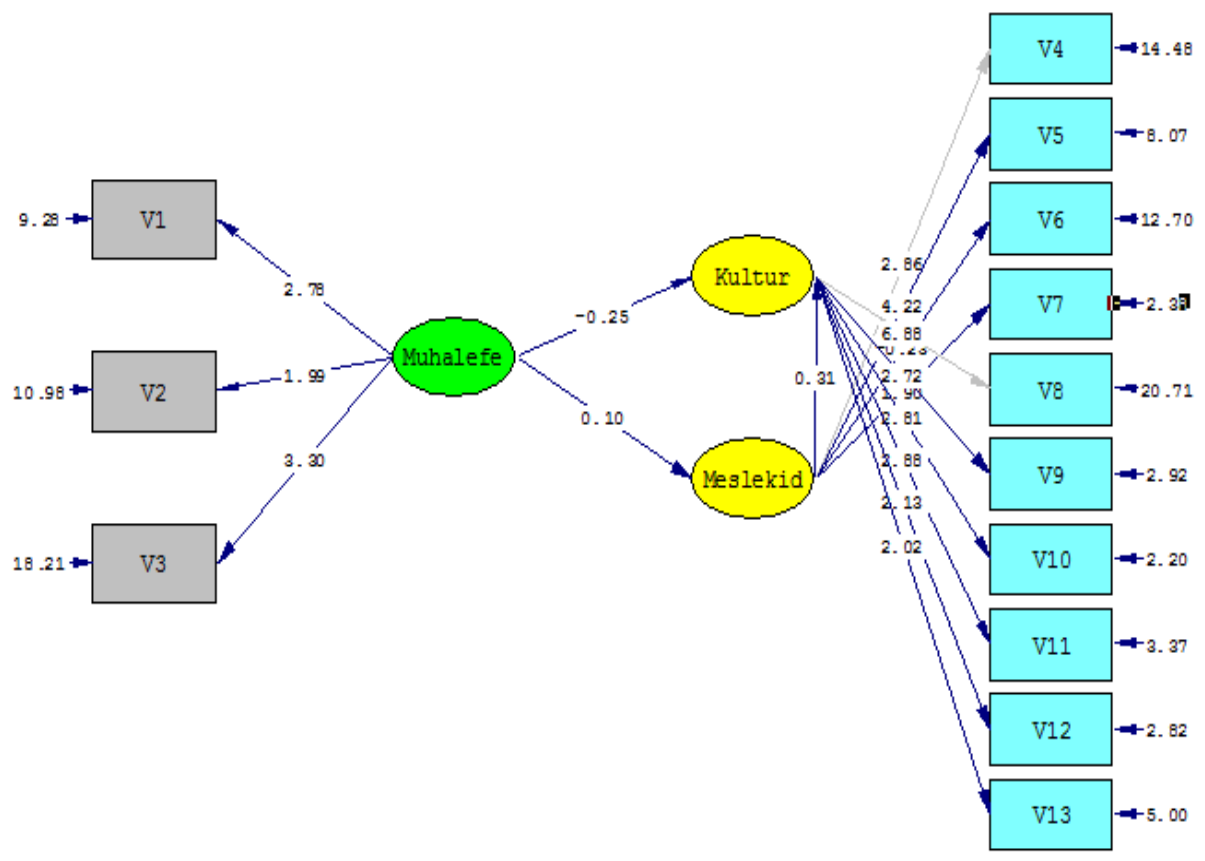

Şekil 2. Öğretmenlerin okul kültürüne ilişkin görüşleri ve örgütsel muhalefet davranışları arasındaki ilişkide meslekî değerlerin aracılığı modeli.

Şekil 2'de görüldüğü gibi, öğretmenlerin örgütsel muhalefet davranışları ve meslekî değerleri ile örgütsel muhalefet davranışları ve 
okul kültürü arasında doğrudan ilişki kurulmuş, ayrıca örgütsel muhalefet davranışları ile okul kültürü arasında meslekî değerlerin aracılık etkisini gösteren dolaylı bir ilişkide modele dâhil edilmiştir. Söz konusu yapısal modele ilişkin uyum iyiliği indeksleri incelendiğinde, $\mathrm{x}^{2}=321.47, \quad \mathrm{sd}=62, \quad p=0.00, \quad \mathrm{CFI}=0.94, \quad \mathrm{AGFI}=0.88, \quad \mathrm{NFI}=0.93$, S-RMR=0.07, RMSEA=0.08 olarak elde edilmiş, söz konusu değerler belirlenen hipotezleri desteklemiştir.

Birinci hipotez öğretmenlerin örgütsel muhalefet davranışları ile okul kültürüne ilişkin görüşlerinin doğrudan ilişkili olduğu şeklindedir ve bu hipotez doğrulanmıştır. Araştırmadan elde edilen bulgular, öğretmenlerin örgütsel muhalefet davranışlarının okul kültürüne ilişkin görüşleri ile negatif yönde ilişkili olduğunu göstermiştir. Bu bulguya göre öğretmenlerin çalıştıkları kurumda muhalefet davranışları arttıkça okul kültürüne ilişkin görüşleri ters yönde değişmektedir.

İkinci hipotez öğretmenlerin meslekî değerleri ile okul kültürüne ilişkin görüşlerinin doğrudan ilişkili olduğu şeklindedir ve bu hipotez doğrulanmıştır. Araştırmadan elde edilen bulgular, öğretmenlerin meslekî değerleri ile okul kültürüne ilişkin görüşlerinin pozitif yönde ilişkili olduğunu göstermiştir. Bu bulguya göre öğretmenlerin meslekî değerleri ile okul kültürüne ilişkin görüşleri aynı yönde değişmektedir.

Üçüncü hipotez öğretmenlerin örgütsel muhalefet davranışları ile meslekî değerlerinin doğrudan ilişkili olduğu şeklindedir ve bu hipotez doğrulanmıştır. Araştırmadan elde edilen bulgular, öğretmenlerin muhalefet davranışları ile meslekî değerlerinin pozitif yönde ilişkili ol- 
duğunu göstermiştir. Bu bulguya göre öğretmenlerin muhalefet davranışları ile meslekî değerleri aynı yönde değişmektedir.

Dördüncü hipotez öğretmenlerin örgütsel muhalefet davranışları ile okul kültürüne ilişkin görüşleri, meslekî değerleri aracılığı ile ilişkilidir ve bu hipotez doğrulanmıştır. Araştırmadan elde edilen bulgular, öğretmenlerin örgütsel muhalefet davranışları ile okul kültürüne ilişkin görüşleri arasında doğrudan ilişki olduğunu; ancak bu ilişkiye meslekî değerler dâhil edildiğinde meslekî değerlerin örgütsel muhalefet davranışları ile okul kültürüne ilişkin görüşleri arasında kısmî aracı değişken olduğunu ortaya koymaktadır.

Yapısal eşitlik denkleminde yer alan değişkenlerin katsayısına bakılarak kurulan modelde öğretmenlerin örgütsel muhalefet davranışlarının meslekî değerlerini ve okul kültürüne ilişkin görüşlerini istatistiksel olarak anlamlı bir şekilde yordadığ nan varyans miktarı incelendiğinde okul kültürünün \%31'i meslekî değerler ve \%25'i örgütsel muhalefet davranışları tarafindan açıklanırken, meslekî değerlerin \%10’u örgütsel muhalefet davranışları tarafından açıklanmaktadır.

\section{Tartışma}

Araştırma sonucunda; öğretmenlerin örgütsel muhalefet davranışları ile okul kültürüne ilişkin görüşlerinin doğrudan ilişkili olduğu şeklindeki hipotez doğrulanmıştır. Öğretmenlerin örgütsel muhalefet davranışlarının okul kültürüne ilişkin görüşleri ile negatif yönde ilişkili olduğu görülmüştür. Bu durum okullarında güçlü bir örgüt kültürünün 
varlığına inanan, bu kültürü oluşturma ve sürdürmede katkı sağladıklarını düşünen, yani örgüt kültürüne ilişkin görüşleri güçlü olan öğretmenlerin örgütsel muhalefet davranışı sergilemek için daha az çaba gösterdiklerini düşündürmektedir. Okul kültürünü benimseyen ve bu kültüre uyum gösteren öğretmenler, işlerinde daha verimlidirler ve muhalefet davranışları yerine olumlu davranışlar göstermektedirler. Özdemir (2013), öğretmenlerin örgütsel muhalefete ilişkin görüşlerini incelediği araştırmasında okullarda öğretmen muhalefetini etik dışı, hukuk dışı ve zorbaca davranışlar sergileyen yönetici tutumlarının tetiklediğini saptamıştır. Öğretmenlerin en sık sergiledikleri muhalif davranış ise doğrudan yöneticiye itiraz etmektir. Araştırmada ayrıca, yöneticilerin muhalif öğretmenleri baskı altına almaya çalıştıkları ve muhalefetin yöneticiler üzerinde olumsuz sonuçlar doğurduğu görülmüştür. Buna karşın muhalefetin okullarda özdenetim, demokrasi, adalet ve örgütsel yenileşme üzerinde olumlu etkilerinin olduğu saptanmıştır. Özdemir (2011) çalışmasında, kamu liselerinde görev yapan yönetici görüşlerine göre, okullarda öğretmen muhalefetini tetikleyen nedenleri, muhalif öğretmenlerin nasıl davrandığını ve muhalefetin öğretmen, yönetici ve okul üzerinde ne tür sonuçlara yol açtığını araştırmıştır. Araştırma sonucunda öğretmenlerin en çok, kendilerine verilen görevlere muhalefet ettikleri görülmüştür. Araştırmada ortaya çıkan bir diğer sonuç ise, öğretmenlerin muhalefete neden olan yönetici davranışları karşısında çoğunlukla 'küsme' davranışını sergiledikleridir. Okul yöneticileri muhalif öğretmenlere hoşgörü ile yaklaştıklarını ve onlara yönelik olumsuz bir tutum takınmadıklarını ifade etmişlerdir. Buna karşın yöneticiler, muhalefetin kendilerini okulda huzursuz eden 
bir etmen olduğu yönünde görüş bildirmişlerdir. Diğer yandan yönetici görüşlerine göre muhalefetin okul üzerinde yıkıcı sonuçlara yol açtığı da görülmüştür.

Öğretmenlerin meslekî değerleri ile okul kültürüne ilişkin görüşlerinin doğrudan ilişskili olduğu şeklindeki hipotez doğrulanmıştır. Öğretmenlerin meslekî değerlerinin, okul kültürüne ilişkin görüşleri ile pozitif yönde ilişkili olduğu görülmüştür. Örgüt kültürünün bir kurum, kuruluş veya takımdaki üyelerin paylaştığı gelenekler, duygular, inançlar, değerler, anlayışlar ve davranışlar bütünü olduğu düşünüldüğünde güçlü bir okul kültürü yaratmada öğretmenlerin meslekî değerlerinin öneminin büyük olduğu söylenebilir. Örgüt kültürünün çeşitli tanımlarında yer alan ve dikkat çeken ortak noktası, kültürün paylaşılan değerlerden meydana geldiği ve örgüt kültürünün özünü oluşturduğudur. Demirtaş (2012) araştırmasında, ilkokul ve ortaokul öğretmenlerinin görüşlerine göre, okul yöneticisinin değere dayalı yönetim uygulamalarının okul kültürü üzerindeki etkisini incelemiş ve elde edilen yapısal eşitlik modelinin, değerlere göre yönetimin okul kültürünü anlamlı düzeyde etkilediği ortaya çıkmıştır. Araştırma bulgularına göre, okul kültürünü etkilemede yöneticilerin sahip olduğu örgütsel değerlerin etkisi, bireysel değerlerin etkisinin iki katına yakındır. Ayrıca, değerlere göre yönetimin okul kültürünün bütün boyutları üzerinde anlamlı etkisi vardır. En yüksek tesir ise katılım boyutunda gerçekleşmiştir. Bu boyutu sırasıyla denetim, toplantılar, iletişim ve iklim boyutları izlemektedir. Firat (2010), ilkokul ve ortaokullarda görev yapan okul müdürü ve öğretmenlerin okul kültürüne ve değer 
sistemlerine ilişkin görüşlerinin ne olduğunu ve aralarındaki ilişkileri ortaya çıkarmayı amaçlamıştır. Araştırma bulgularına göre okul müdürleri "iyilikseverlik" değer boyutuna öğretmenlerden, öğretmenler de "hazcılık”, “öz yönelim” ve "güvenlik" değer boyutlarına okul müdürlerinden daha fazla önem yüklemişlerdir. Hem okul müdürlerinin hem de öğretmenlerin okul kültürüne ilişkin görüşleri ile değer sistemlerine ilişkin görüşleri arasında önemli ilişki saptanmıştır.

Üçüncü hipotez, öğretmenlerin örgütsel muhalefet davranışları ile meslekî değerlerinin doğrudan ilişkili olduğu şeklindedir. Araştırmanın bu hipotezi doğrulanmıştır. Öğretmenlerin muhalefet davranışları ile meslekî değerleri pozitif yönde ilişkilidir. Örgütsel muhalefeti, örgüt içerisinde meydana gelen bazı uygulamalardan hoşnutsuzluk duyulması sonucu ortaya çıkan ve bu anlamda örgütsel statükodan bir uzaklaşmayı simgeleyen her türlü protesto ve karşı gelme davranışı olduğu düşünüldüğünde, öğretmenlerin meslekî değerlerinin oluşmasında muhalefet davranışlarının öneminin büyük olduğu söylenebilir. Yıldız (2013)'ün araştırmasında, örgütsel bağl1lık ile örgütsel sinizm ve örgütsel muhalefet görüşleri arasında bir ilişki olduğu sonucuna ulaş1lmıştır. Öğretmenlerin örgütsel bağl1lık ile örgütsel sinizm görüşleri arasında yüksek seviyede negatif, örgütsel muhalefet görüşleri ile ise orta seviyede negatif bir ilişki olduğu sonucuna ulaşılmıştır.

Dördüncü hipotez; öğretmenlerin örgütsel muhalefet davranışları ile okul kültürüne ilişkin görüşlerinin, meslekî değerleri aracıllğ 1 ile ilişkili olduğu şeklindedir. Araştırmanın bu hipotezi doğrulanmıştır. Araştırmadan elde edilen bulgu, öğretmenlerin örgütsel muhalefet 
davranışları ile okul kültürü arasında doğrudan ilişki olduğunu ancak bu ilişkiye meslekî değerler dâhil edildiğinde, meslekî değerlerin kısmî aracı değişken olduğunu ortaya koymaktadır.

\section{Sonuç}

Araştırma sonucunda; öğretmenlerin örgütsel muhalefet davranışları ile okul kültürüne ilişkin görüşlerinin, öğretmenlerin meslekî değerleri ile okul kültürüne ilişkin görüşlerinin ve öğretmenlerin örgütsel muhalefet davranışları ile meslekî değerlerinin doğrudan ilişkili olduğu görülmüştür. Öğretmenlerin örgütsel muhalefet davranışları ile okul kültürü arasında doğrudan ilişki olduğu; ancak bu ilişkiye meslekî değerler dâhil edildiğinde, meslekî değerlerin kısmî aracı değişken olduğu bulunmuştur. Araştırma sonuçlarına göre okul yöneticilerinin örgütsel muhalefet ve meslekî değer değişkenlerini yönetsel uygulamalarında göz önünde bulundurabilecekleri önerilebilir. Ayrıca, okul kültürü üzerinde aracılık etkisi olan diğer değişkenler araştırılabilir.

\section{Kaynakça}

Atay, K. (2001). Öğretmen yönetici ve denetmenlerin bakış açısından okul kültürü ve öğretmenlerin verimliliğine etkisi. Kuram ve Uygulamada Ĕ̆itim Yönetimi, 7(26), 179-194.

Ayık, A. (2007). Illköğretim okullarında oluşturulan okul kültürü ile okulların etkililiği arasındaki ilişki (Erzurum ili örneği). Yayınlanmamış doktora tezi, Atatürk Üniversitesi Sosyal Bilimler Enstitüsü.

Balc1, A. (2011). Sosyal bilimlerde araştırma yöntem, teknik ve ilkeler. Ankara: Pegem Akademi. 
Büyüköztürk, Ş., Kılıç, E., Akgün,Ö., Karadeniz, Ş. ve Demirel, F. (2011). Bilimsel araştırma yöntemleri. Ankara: Pegem Akademi.

Çelik, V. (2000). Okul kültürü ve yönetimi. Ankara: Pegem Akademi.

D'Andrade, R. (2008). A study of personal and cultural values. New York: Palgrave MacMillan.

Demirtaş, Z. (2012). İlköğretim okulu yöneticilerinin değerlere dayalı yönetim uygulamalarının okul kültürüne etkisi. Kuram ve $U y$ gulamada Ĕ̌itim Yönetimi,18(4), 523-544.

Denison, D. R. (1990). Corporate culture and organizational effetiveness. New York: Wiley.

Erdem, F. ve İşbaşı, J. Ö. (2000). Takım çalışmalarında güven ve güvensizlik: performans için koşulsuz güven mi, optimum güven mi? 25-27 Mayıs, Nevşehir, 8. Ulusal Yönetim ve Organizasyon Kongresi.

Eren, E. (2001). Örgütsel davranış ve yönetim psikolojisi. İstanbul: Beta.

Frrat, N. (2010). Okul müdürü ve öğretmenlerin okul kültürü ile değer sistemlerine ilişkin görüşleri, Eğitim ve Bilim, 35(156), 71-82.

Hofstede, G. H. (2001). Culture's consequences (2. bask1). Thousand Oaks, CA: Sage.

Hoyle, R. H. (1995). Structural equation modeling. Thousand Oaks, California: Sage.

Kassing, J. W. (1998). Development and validation of the organizational dissent scale. Management Communication Quarterly, 2, 183-229. 
Kline, R. B. (2011). Principles and practice of structural equation modeling. New York: The Guilford.

Lencioni, P. M. (2002). Make your values mean something. Harvard Business Review, 80, 113-117.

Meek, L. (1988). Organizational culture: Origins and weaknesses. Organization Studies, 9, 453-473.

Özdemir, A. (2006). Okul kültürünün oluşturulması ve çevreye tanıtılmasında okul müdürlerinden beklenen ve onlarda gözlenen davranışlar. Türk Eğitim Bilimleri Dergisi, 4(4), 411-433.

Özdemir, M. (2010). Ankara ili kamu genel liselerinde görev yapan yönetici ve öğretmenlerin örgütsel muhalefete ilişkin görüşleri. Yayınlanmamış doktora tezi, Ankara Üniversitesi Eğitim Bilimleri Enstitüsü.

Özdemir, M. (2013). Genel liselerde görev yapan öğretmenlerin örgütsel muhalefete ilişkin görüşleri (Ankara ili örneği). Eğitim ve Bilim, 38(168), 113-128.

Özdemir, M. (2011). Lise yöneticilerinin öğretmenlerin örgütsel muhalefet davranışlarına ilişkin görüşleri. Kuram ve Uygulamada Ĕ̈itim Bilimleri, 11(4), 1895-1908.

Pettigrew, A. (1979). On studying organizational cultures, Administrative Science Quarterly, 24(4), 570-581.

Posner, B. Z. (2010). Another look at the impact of personal and organizational values congruency. Journal of Business Ethics, 97, 535-541.

Schein, E. H. (1984). Coming to a new awareness of organizational culture. Sloan Management Review, 25(2), 3-16. 
Schermelleh-Engel, K., Moosbrugger, H. ve Müller, H. (2003). Evaluating the fit of structural equation models: Test of significance and descriptive goodness-of-fit measures. Methods of Psychological Research Online, 8(2), 23-74.

Sezgin, F. (2007). İlköğretim okulu öğretmenlerinin bireysel ve örgütsel değerlere ilişkin önem sıralamaları. Gazi Eğitim Fakültesi Dergisi,27(1), 59-85.

TDK, (2013). Türkçe sözlük. Ankara: TDK.

Tezcan, C. (2008). Yapısal eşitlik modelleri. Yayınlanmamış yüksek lisans tezi, Hacettepe Üniversitesi Fen Bilimleri Enstitüsü.

Topkaya, N. (2011). Psikolojik yardım alma niyetinin sosyal damgalanma, tedavi korkusu, beklenen yarar, beklenen risk ve tutum faktörleriyle modellenmesi. Yayınlanmamış doktora tezi, Ege Üniversitesi Sosyal Bilimler Enstitüsü.

Tunca, N. ve Sağlam, M. (2013). İlköğretim öğretmenlerine yönelik mesleki değerler ölçeğinin geçerlik ve güvenirlik çalışması, $E \breve{g} i$ tim Bilimleri Araştırmaları Dergisi,3(1), 139-164.

Yılmaz, V. ve Çelik, E. H. (2009). Yapısal eşitlik modellemesi-I. Ankara: Pegem Akademi.

Yıldız, K. (2013). Örgütsel bağlllık ile örgütsel sinizm ve örgütsel muhalefet arasındaki ilişki. Turkish Studies, 6(8), 853-879. 